\title{
Effect of Austenitization Temperature on Microstructure and Mechanical Properties of B1500HS Boron Steel in the Hot Stamping
}

\author{
Lianfang $\mathrm{HE}^{\mathrm{a}}$, Huiping $\mathrm{LI}^{\mathrm{b}}$ and Cheng $\mathrm{WANG}^{\mathrm{c}}$ \\ School of Materials Science and Engineering, Shandong University of Science and Technology, \\ Qingdao 266590, PR China

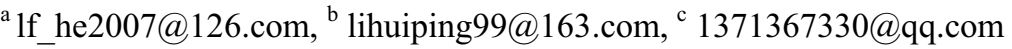

\begin{abstract}
In the paper, a typical part of B1500HS boron steel was formed using the hot stamping tools, and the effect of austenitization temperature on the microstructure and mechanical properties of B1500HS boron steel was studied. The results show that, the temperature of steel plate has a significant effect on the temperature of hot stamping tools, and the temperature of punch rises at a faster speed than that of die in the hot stamping process. The austenitization temperature has a significant effects on the size of martensite. The cooling rate of steel plate has a significant effect on the tensile strength when the austenitization temperature is $870{ }^{\circ} \mathrm{C}$. The fracture of sample austenitized at $870{ }^{\circ} \mathrm{C}$ or $900{ }^{\circ} \mathrm{C}$ is the dimple, the fracture of sample austenitized at $930{ }^{\circ} \mathrm{C}$ or $960{ }^{\circ} \mathrm{C}$ is the mixture of quasicleavage and dimple.
\end{abstract}

Keywords: Hot stamping, Austenitization temperature, Microstructure, Mechanical properties

\section{Introduction}

In order to reduce vehicle weight and tail-gas emission without compromising crash performance, most of automotive manufacturers focus upon application of new materials besides optimizing framework of vehicle. Body-in-white or BIW, in which a car body's sheet metal components have been welded together, is the largest structure of vehicle, and main contributor to the vehicle weight, so it is one of the best objectives of weight reduction. Mechanical performance of BIW can be improved with the weight reduction by using advanced high-strength steel (AHSS) or ultra high-strength steel (UHSS). But formability of AHSS or UHSS reduces remarkably with the enhancement of strength, and some defects, such as poor forming quality, cracking and spring-back, are easy to appear in the cold stamping. At present, lots of research about the hot stamping of quenchable boron steel has been done in the world, such as the investigation of high-strength steel forming technology [1], formability of quenchable boron steel in the hot stamping [2], design of hot stamping tools with cooling system [3], constitutive relationships of boron steel at high temperature [4] and numerical simulation of hot stamping process [5]. 
In the paper, a typical part of B1500HS boron steel is formed using the hot stamping tools, and the effect of austenitization temperature on the microstructure and mechanical properties of B1500HS boron steel is studied.

\section{Experiments}

\subsection{Material}

The material used in the paper is B1500HS boron steel sheet with $1.6 \mathrm{~mm}$ thickness and non-coating. The chemical compositions of $\mathrm{B} 1500 \mathrm{HS}$ are $0.23 \% \mathrm{C}, 0.25 \% \mathrm{Si}, 1.35 \% \mathrm{Mn}$, $0.19 \% \mathrm{Cr}, 0.003 \% \mathrm{~B}$ and $\mathrm{Fe}$. The samples which are used to test the microstructure and mechanical performance are cut from the region I, II and III of stamped parts by the wire electric discharge machine (WEDM), as shown in Fig. 1.

\subsection{Quenching experiments}

Hot stamping tools used in the experiment are shown in Fig. 2. The thermocouple positions are marked as symbol (1)、(2)、(3) and (4). The material of tools is H13 steel. The maximum speed of forming machine is about $20 \mathrm{~mm} / \mathrm{s}$. NiCr-NiSi thermocouples with the diameter of $2 \mathrm{~mm}$ and length of $100 \mathrm{~mm}$ are used to measure the temperature of tools.

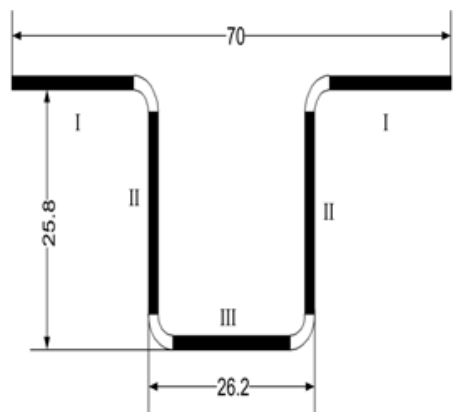

Fig. 1 Hot stamping part (unit: $\mathrm{mm}$ )

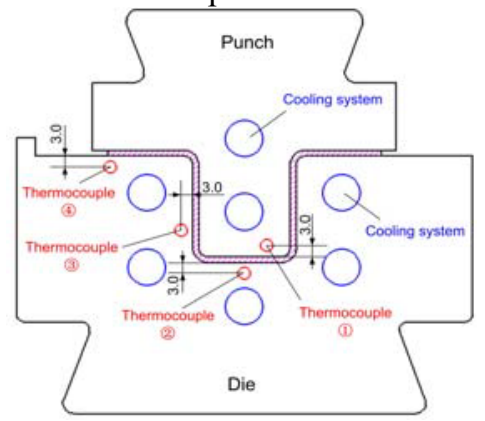

Fig. 2 Hot stamping tools (unit: $\mathrm{mm}$ )

\section{Experiment Results and Discussions}

\subsection{Temperature of completely austenitization}

The temperature (Ac1) at which pearlite transforms into austenite is about $725^{\circ} \mathrm{C}$ for $\mathrm{B} 1500 \mathrm{HS}$ steel, and the temperature (Ac3) at which ferrite transforms into austenite is about $810^{\circ} \mathrm{C}$, when the heating rate is about $200{ }^{\circ} \mathrm{C} / \mathrm{h}$. The heating rate of steel plates in the furnace SX2-4-10G is much higher than $200{ }^{\circ} \mathrm{C} / \mathrm{h}$, and the heating rate has a significant effect on the temperature Ac1 and Ac3 [6]. In order to know the temperature curve of steel plate in the heating and cooling, a thermocouple is welded on the side of steel plate. The position of thermocouple is shown in Fig. 3.

The temperature curve shown in Fig. 3 can be divided into six stages: 1 - heating in the furnace, 2 - transporting (free cooling), 3 - contacting with the punch, 4 - forming in the tools, 5 - cooling in the tools, 6 - out of die and cooling in the air. According to the variation tendency of temperature curve in the heating process, the temperature Ac1 and 
Ac3 are about $776.8{ }^{\circ} \mathrm{C}$ and $824.4{ }^{\circ} \mathrm{C}$ when the boron steel $\mathrm{B} 1500 \mathrm{HS}$ is heated in the furnace.

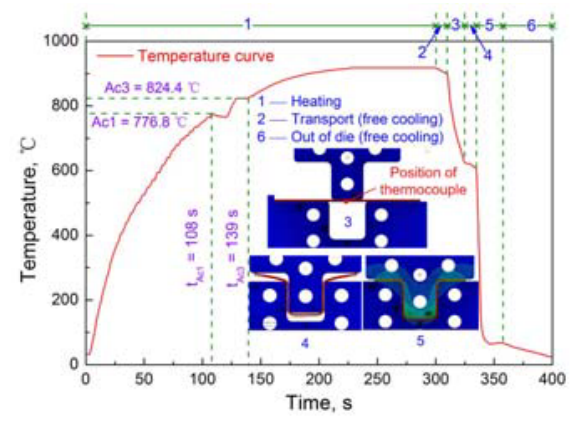

Fig.3 Temperature curve of part

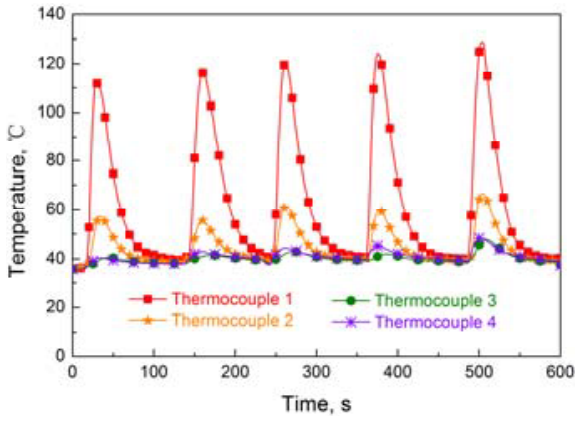

Fig.4 Temperature curves of tools

\subsection{Temperature of tools}

In the hot stamping, temperatures of four positions marked with symbol (1)、(2)、(3) and (4) shown in Fig. 2 are measured by thermocouples. When the austenitization temperature is $870^{\circ} \mathrm{C}$, the temperature curves are shown in Fig. 4. The temperature curves relative to other austenitization temperature are similar to those at $870^{\circ} \mathrm{C}$.

Before the punch contacts with the heated boron steel plate, the steel plate only contacts with the upper surface of die. Only a little heat energy transfers from the steel plate to the die, as the boundary heat transfer coefficient is smaller [7]. When the die contacts with the plate, the plate instantaneously separates from the upper surface of die, and begins deforming and sliding into the die with the punch, as shown in the fourth stage of Fig. 3. So the contact time between the steel plate and the upper surface of die is very short, and the temperature variations at the positions (4) just have a little change in the hot stamping, as shown in Fig. 4.

When the steel plate completely contacts with the bottom surface of punch and the lower surface of die, as shown in the fifth stage of Fig. 3, the pressure among them rapidly reaches to over $30 \mathrm{MPa}$. Much heat energy transfers from the steel plate to the die and punch, as the boundary heat transfer coefficient is relative to the pressure [8]. The temperature variation at the position (1) is significant, but the temperature variation at the position (2) is smaller than that at the position (1), as shown in Fig. 4. The main reason is that, the thickness of punch is small (about $24 \mathrm{~mm}$ ). Moreover, the volume of die is much larger than that of punch, so the temperature variation of the die is slower than that of the punch when the same heat energy is absorbed.

For the region II of forming part shown in Fig. 1, it is in the gap of the punch and die. Because the gap is a little larger than the thickness of steel plate, the clearance may appear among the punch, die and stamped part. The heat exchange between the forming part, punch and die is similar to the heat exchange without pressure. So the temperature variation at the position (3) is smaller, as shown in Fig. 4.

The temperature variations of punch and die in Fig. 4 show that, the temperatures of punch and die instantaneously rise and rapidly decrease under the action of the hot stamped part and tool cooling system, and the punch is easier to get higher temperature. The temperature of punch and die is one of the key factors to affect the microstructure and mechanical performance of forming part. If no cooling system works in the tools, the temperature of tools would become higher and higher. The microstructure and mechanical 
performance of hot stamped part would be affected. In addition, the service life of tools would be affected.

\subsection{Microstructure}

The metallographic samples are polished, and then etched using 4\% nitric acid alcohol solution. The microstructures of samples are the lath martensite.

For the same hot stamped part, microstructures in the region I, II, and III is similar, when the austenitization temperature is in the range of $870{ }^{\circ} \mathrm{C}-960{ }^{\circ} \mathrm{C}$. The results of microstructure show that, the austenitization temperature has a significant effect on the size of martensite, the size of lath martensite becomes bigger and bigger with increasing austenitization temperature, as the grain size of austenite is coarser and coarser with increasing austenitization temperature. The microstructures relative to different austenitization temperature are shown in Fig. 5.

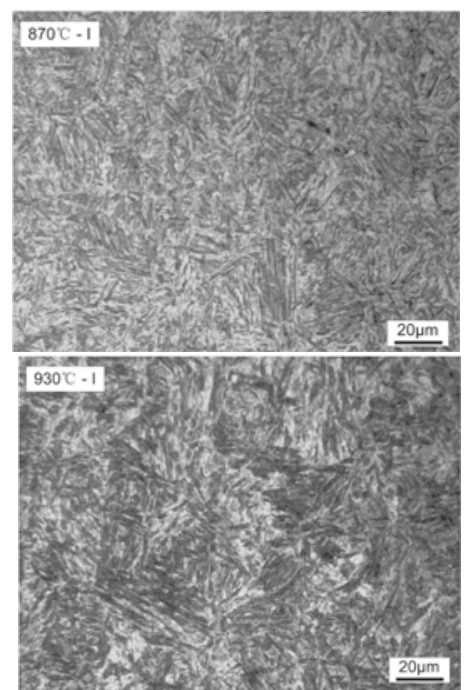

(a) $870{ }^{\circ} \mathrm{C}$

(b) $900{ }^{\circ} \mathrm{C}$

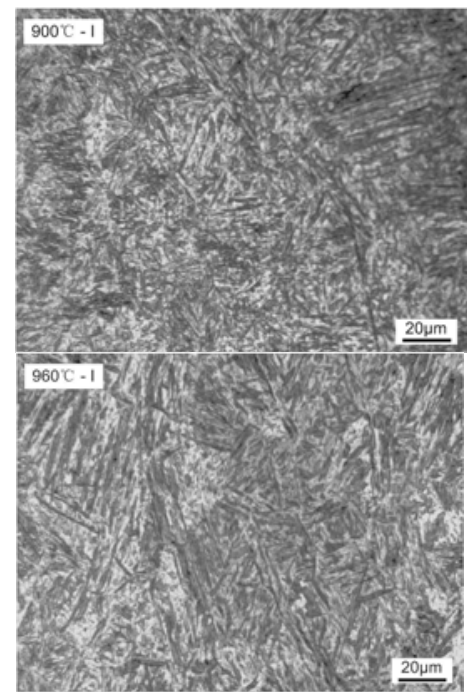

(c) $930{ }^{\circ} \mathrm{C}$ (d) $960{ }^{\circ} \mathrm{C}$

Fig.5 Microstructures relative to different austenitization temperature

\subsection{Stress and strain}

The tensile samples are done the static tensile test by CMT5000 tensile testing machine. The true stress and strain curves are shown in Fig. 6. These curves show that, the elongation and tensile strength of the sample at austenitization temperature $870^{\circ} \mathrm{C}$ is a little higher than that at other austenitization temperatures, as the grain size of austenite and size of lath martensite are finer, as shown in Fig. 5. 


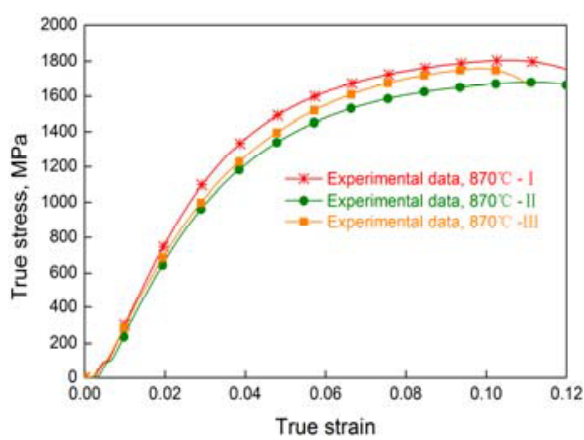

(a) $870^{\circ} \mathrm{C}$

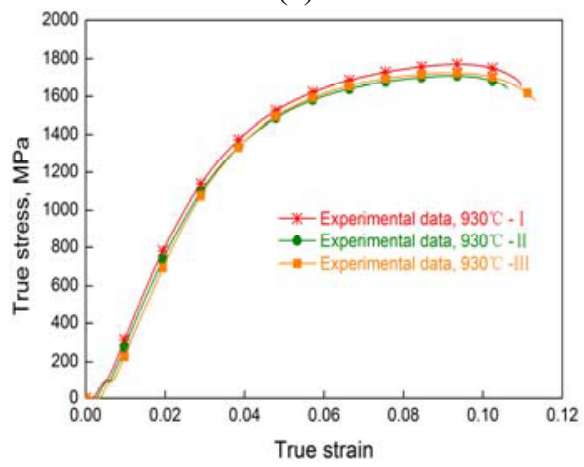

(c) $930^{\circ} \mathrm{C}$

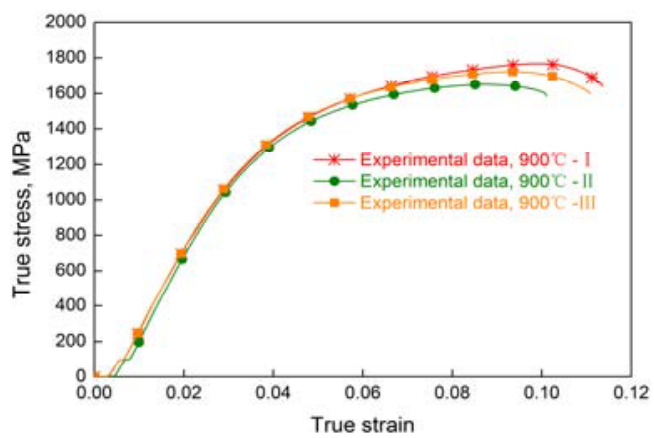

(b) $900^{\circ} \mathrm{C}$

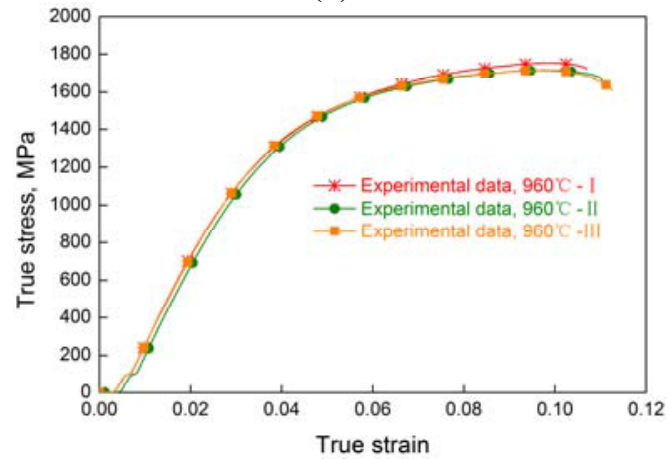

(d) $960^{\circ} \mathrm{C}$

Fig.6 True strain-stress curves of sample at the region I, II and III

The tensile strength of the sample at the region II is a little less than that at the region I and III, as the cooling rate at region II is lower than that at other regions. When the austenitization temperature of steel plate is $870^{\circ} \mathrm{C}$ or $900^{\circ} \mathrm{C}$, the difference of tensile strengths of sample at the region I, II and III is about $130 \mathrm{MPa}$. When the austenitization temperature of steel plate is $930^{\circ} \mathrm{C}$ or $960^{\circ} \mathrm{C}$, the tensile strengths at the region I, II and III are approximately same.

The curves in Fig. 6 show that, the elongation and tensile strength of the sample at austenitization temperature $870^{\circ} \mathrm{C}$ is a little higher than that at other austenitization temperatures, as the grain size of austenite and size of lath martensite are finer, as shown in Fig. 5.

The tensile strength of the sample at the region II is a little less than that at the region I and III, as the cooling rate at region II is lower than that at other regions. When the austenitization temperature of steel plate is $870^{\circ} \mathrm{C}$ or $900^{\circ} \mathrm{C}$, the difference of tensile strengths of sample at the region I, II and III is about $130 \mathrm{MPa}$. When the austenitization temperature of steel plate is $930^{\circ} \mathrm{C}$ or $960^{\circ} \mathrm{C}$, the tensile strengths at the region I, II and III are approximately same.

Except the part with the high and uniform strength, the hot stamping can also be used to manufacture the structural components with distributed properties. The curves in Fig. 6 show that, the lower austenitization temperature is helpful for manufacturing the structural components with distributed properties by introducing a thin air gap between the tools and steel plate, or using the tool materials with the lower thermal conductivity, as the austenite attained at the lower austenitization temperature is particularly susceptible to the cooling rate. 


\subsection{Fracture morphology}

The fracture morphology of sample austenitized at $870{ }^{\circ} \mathrm{C}, 900{ }^{\circ} \mathrm{C}, 930{ }^{\circ} \mathrm{C}$ or $960{ }^{\circ} \mathrm{C}$ is shown in Fig. 7. All the fracture are the ductile fracture, the fracture of sample austenitized at $870{ }^{\circ} \mathrm{C}$ or $900{ }^{\circ} \mathrm{C}$ is the dimple, the fracture of sample austenitized at $930{ }^{\circ} \mathrm{C}$ or $960{ }^{\circ} \mathrm{C}$ is the mixture of quasicleavage and dimple, and the size of dimple rises with the increase of austenitization temperature.
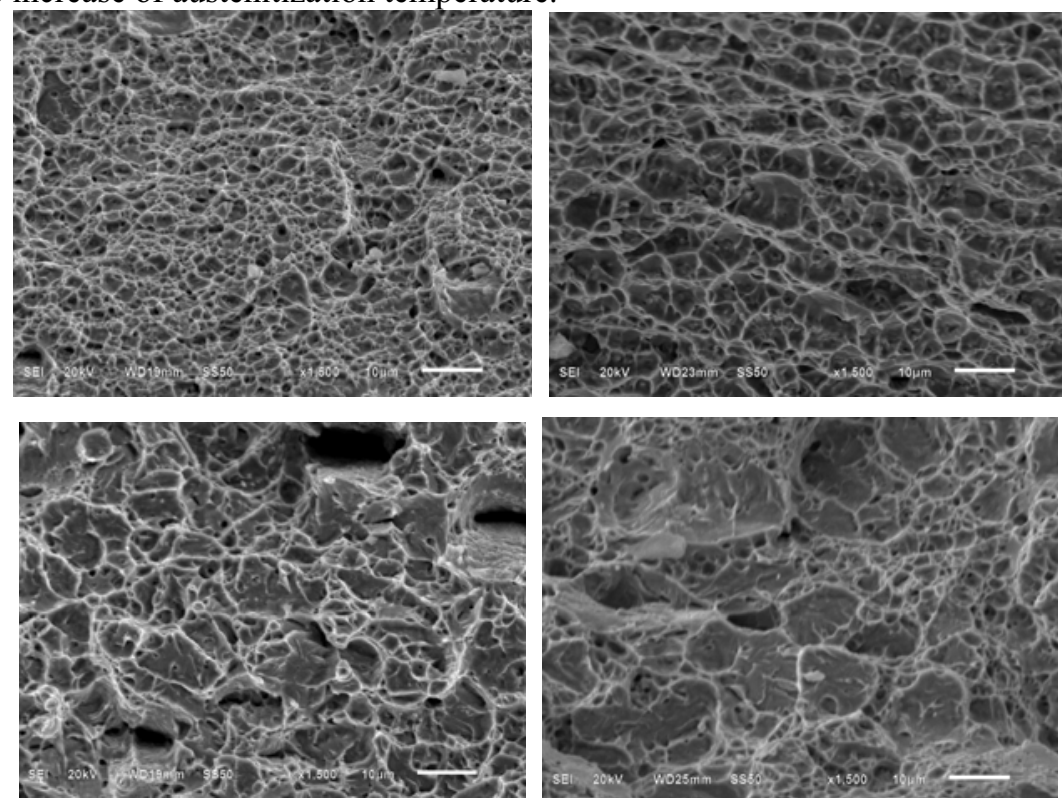

(a) $870^{\circ} \mathrm{C}$

(b) $900^{\circ} \mathrm{C}$

(c) $930^{\circ} \mathrm{C}$

(d) $960^{\circ} \mathrm{C}$

Fig.7 Fracture morphologies at different austenitization temperature

According the temperature curve shown in Fig. 2, pearlite and ferrite can fully transform into austenite when the austenitization temperature is over $824.4{ }^{\circ} \mathrm{C}$. In the holding temperature process, the segregation of impurity elements (such as $\mathrm{P}, \mathrm{S}, \mathrm{Si}, \mathrm{Ti}$, etc) for B1500HS can occur on the grain boundary of austenite due to higher austenitization temperature. Some defect such as voids is easy to appear on the grain boundary due to segregation of impurity elements, and it can grow with the increase of austenitization temperature.

When the tension is put on the sample with the void defect, the voids can grow during deformation until they link together. Some continuous fracture paths may come into being, and some dimples can appear on the fracture of sample. The smaller dimple due to the fine grain size of austenite is helpful for the increase of tensile strength and elongation of sample. With the increase of austenitization temperature, the grain size of austenite and size of lath martensite become larger and larger, more and more quasicleavages occur on the fracture. All these are harmful to the tensile strength, can cause the tensile strength of the sample austenitized at $900{ }^{\circ} \mathrm{C}, 930{ }^{\circ} \mathrm{C}$ or $960{ }^{\circ} \mathrm{C}$ is less than that at $870{ }^{\circ} \mathrm{C}$.

\section{Conclusions}

Some conclusions are as follows:

1. The temperatures of punch and die rise due to the heated steel plate, and the punch is easier to get higher temperature than the die. Cooling system in the punch and 
die is very necessary for improving the microstructure and mechanical performance of hot stamped part.

2. The austenitization temperature has significant effects on the size of martensite, the size of lath martensite becomes bigger and bigger with increasing austenitization temperature.

3. The cooling rate has a significant effect on the tensile strength when the austenitization temperature is $870{ }^{\circ} \mathrm{C}$. The lower austenitization temperature is helpful for manufacturing the structural components with distributed properties.

4. The fracture of hot stamped part austenitized at $870{ }^{\circ} \mathrm{C}$ or $900{ }^{\circ} \mathrm{C}$ is the dimple, the fracture of part austenitized at $930{ }^{\circ} \mathrm{C}$ or $960{ }^{\circ} \mathrm{C}$ is the mixture of quasicleavage and dimple, and the size of dimple rises with the increase of austenitization temperature.

\section{Acknowledgements}

This work was financially supported by National Natural Science Foundation of China (51175302, 51575324), Program for New Century Excellent Talents in University (NCET-12-0342), Science and Technology Program of Shandong and Huangdao (2014GGX103024, 20140132).

\section{References}

1. R. Kolleck, R. Veit, M. Merklein, et al. Investigation on induction heating for hot stamping of boron alloyed steels. Cirp Ann Manuf Techn, 58( 2009) 275-278.

2. J.Y. Min, J.P. Lin, J.Y. Li, W.H. Bao. Investigation on hot forming limits of high strength steel 22MnB5. Comp Mater Sci, 49(2010) 326-332.

3. M. Nikravesh, M. Naderi, G.H. Akbari. Influence of hot plastic deformation and cooling rate on martensite and bainite start temperatures in 22MnB5 steel. Mat Sci Eng A, 540(2012)24-29.

4. H.P. Li, L.F. He, G.Q. Zhao, L. Zhang. Constitutive relationships of hot stamping boron steel B1500HS based on the modified Arrhenius and Johnson-Cook model. Mat Sci Eng A, 580(2013)330-348

5. H. So, D. Fabann, H. Hoffmann, et al. An investigation of the blanking process of the quenchable boron alloyed steel $22 \mathrm{MnB} 5$ before and after hot stamping process. J Mater Proc Techn , 212(2012)437-449.

6. L.F. He, H.P. Li, K. Gai, et al. Technological parameters optimization and numerical simulation of induction hardening for 55CrMo steel. Trans Mater Heat Treat, 36(2015)199-204

7. B. Abdulhay, B. Bourouga, C. Dessain, et al. Development of estimation procedure of contact heat transfer coefficient at the part-tool interface in hot stamping process. Heat Trans Eng, 32(2011)497-505.

8. P. Hu, L. Ying, Y. Li, Z.W Liao. Effect of oxide scale on temperature-dependent interfacial heat transfer in hot stamping process. J Mater Proc Techn, 213(2013) $1475-1483$ 